\title{
Phylogenetic Diversity in Core Region of Hepatitis C Virus Genotype 1a as a Factor Associated with Fibrosis Severity in HIV-1-Coinfected Patients
}

\author{
Micaela Parra, ${ }^{1,2}$ Natalia Laufer, ${ }^{1,3}$ Julieta M. Manrique, ${ }^{2,3}$ \\ Leandro R. Jones, ${ }^{2,3}$ and Jorge Quarleri ${ }^{1,3}$ \\ ${ }^{1}$ Instituto de Investigaciones Biomédicas en Retrovirus y Sida (INBIRS), Facultad de Medicina, Universidad de Buenos Aires, \\ Paraguay 2155, Piso 11, C1121ABG Buenos Aires, Argentina \\ ${ }^{2}$ Laboratorio de Virología y Genética Molecular (LVGM), Facultad de Ciencias Naturales y Ciencias de la Salud Sede Trelew, \\ Universidad Nacional de la Patagonia San Juan Bosco, 9 de Julio y Belgrano S/N, Chubut, 9100 Trelew, Argentina \\ ${ }^{3}$ Consejo Nacional de Investigaciones Científicas y Técnicas, Av. Rivadavia 1917, C1083ACA Buenos Aires, Argentina \\ Correspondence should be addressed to Jorge Quarleri; quarleri@fmed.uba.ar
}

Received 8 August 2017; Accepted 19 October 2017; Published 12 November 2017

Academic Editor: Fumio Imazeki

Copyright (c) 2017 Micaela Parra et al. This is an open access article distributed under the Creative Commons Attribution License, which permits unrestricted use, distribution, and reproduction in any medium, provided the original work is properly cited.

\begin{abstract}
High hepatitis $\mathrm{C}$ virus (HCV) genetic diversity impacts infectivity/pathogenicity, influencing chronic liver disease progression associated with fibrosis degrees and hepatocellular carcinoma. HCV core protein is crucial in cell-growth regulation and hostgene expression. Liver fibrosis is accelerated by unknown mechanisms in human immunodeficiency virus-1- (HIV-1-) coinfected individuals. We aimed to study whether well-defined HCV-la core polymorphisms and genetic heterogeneity are related to fibrosis in a highly homogeneous group of interferon-treated HIV-HCV-coinfected patients. Genetic heterogeneity was weighed by Faith's phylogenetic diversity (PD), which has been little studied in HCV. Eighteen HCV/HIV-coinfected patients presenting different liver fibrosis stages before anti-HCV treatment-initiation were recruited. Sampling at baseline and during and after treatment was performed up to 72 weeks. At inter/intrahost level, HCV-la populations were studied using molecular cloning and Sanger sequencing. Over 400 complete HCV-la core sequences encompassing 573 positions of $\mathrm{C}$ were obtained. Amino acid substitutions found previously at positions 70 and 91 of HCV-1b core region were not observed. However, HCV genetic heterogeneity was higher in mild than in severe fibrosis cases. These results suggest a potential utility of PD as a virus-related factor associated with chronic hepatitis C progression. These observations should be reassessed in larger cohorts to corroborate our findings and assess other potential covariates.
\end{abstract}

\section{Introduction}

Hepatitis $\mathrm{C}$ virus (HCV) is an enveloped, positive-stranded RNA virus belonging to the genus Hepacivirus in the family Flaviviridae. HCV infection is the major cause of chronic liver disease. Total global viraemic $\mathrm{HCV}$ infections were estimated in 80 (64-103) million infections [1]. Of them, more than 4 million are coinfected with the human immunodeficiency virus (HIV) as both viruses share common transmission routes [2].

HCV-chronic infection is responsible for different hepatic damage including oxidative stress, insulin resistance, steatosis, fibrosis, apoptosis, and hepatocellular carcinoma
(HCC) $[3,4]$. Such alterations are attributed to changes in gene expression patterns in the liver due to virus replication dynamics [5].

Assessment of liver fibrosis has important implications for prognosis and for decision-making on the onset of therapeutic approaches. Liver fibrosis is the excessive accumulation of extracellular matrix proteins as a consequence of chronic aggression on the tissue. In the natural course of HCV infection, advanced liver fibrosis results in cirrhosis and concomitantly in HCC [6]. However, there are extrinsic factors as many as individual-inherent factors that could lead to fibrosis progression. It has been shown that fibrosis progression significantly varies among $\mathrm{HCV}$-infected patients. 
Some of them evolve rapidly into several stages while others evolve into mild fibrosis that could not even progress at all. Some host factors, such as male gender and age at the time of infection, are the two main determinants in the natural course of HCV infection [7]. HIV-related immunosuppression is associated with accelerated liver disease in individuals with HIV/HCV coinfection [8].

HCV genetic variability brings challenges when making generalizations about the aggressiveness of different genotypes and the response to antiviral therapy. Low fidelity RNA-dependent RNA polymerase contributes to increasing mutational rate, generating a collection of closely related genomic variants called quasispecies [9].

Several studies have demonstrated that the highly conserved HCV core protein plays an important role in the pathogenesis and progression of the disease due to its ability to interact with a wide spectrum of viral and cellular proteins, including protooncogenes [10]. Particularly, amino acid substitutions at positions 70 and 91 in the HCV core region have been identified as predictors of hepatocellular carcinoma among genotype 1 b-infected patients from Japan [11-13]. Hence, these polymorphisms might be considered surrogate markers for hepatic disease stages or the eventual development of HCC. However, these mutations have not been assessed in HCV genotype 1a/HIV coinfected patients. Instead other authors have reported the use of other noninvasive test indexes (Forns, APRI, and FIB-4) based on a panel of standard laboratory markers $[14,15]$ as well as an alternative statistical approach based on generalized linear models (GLMs), to identify factors associated with liver disease progression $[16,17]$.

In the present longitudinal study we report the characterization of HCV genotype la core sequences in vivo in HIV coinfected patients and its relationship with hepatic damage. Besides standard analysis including quasispecies heterogeneity, intrahost positive selection pressure, and changes at codons 70 and 91, we analyzed the viral Faith's phylogenetic diversity $(P D)$, which has received little attention in HCV and viruses in general.

\section{Material and Methods}

2.1. Patients. Plasma samples longitudinally collected from eighteen HIV positive patients coinfected with HCV genotype (Gt) 1a were analyzed. For each patient, sampling times include before, during, and at end of interferonbased therapy. Clinical records were reviewed, clinical and laboratory data including $\mathrm{CD} 4^{+} \mathrm{T}$ cell count (flow cytometry double platform, BD FACS Canto; BD Biosciences, San Diego/California, USA) and plasma HCV viral load (VL) by a quantitative reverse transcription- (RT-) PCR assay (COBAS AMPLICOR HCV MONITOR version 2.0; lower limit of quantification of $2.78 \log _{10} \mathrm{IU} / \mathrm{ml}$; Roche Molecular Systems). These parameters were recorded for each sample from each patient during the entire follow-up (Table 1). Patients were treated with anti-HCV pegylated-interferon (peg-IFN) plus ribavirin- (RBV-) based therapy (the standard of care when patients were recruited). They were all on HAART with undetectable HIV-1 RNA ( $<50$ copies/mL).
Liver fibrosis was evaluated by liver biopsy within 12 months before HCV treatment initiation. Results were reported using METAVIR scoring system [18]. Patients were selected for low or high fibrosis scores. Ten patients had absent-to-moderate fibrosis (METAVIR F0-F2), while eight had severe fibrosis-to-cirrhosis (METAVIR F3-F4). Regarding anti-HCV therapy response, three patients were responders (R) (defined as undetectable HCV RNA 24 weeks after treatment completion), and 15 were nonresponders (NR) [19]. Based on the observed scores, patients were categorized as having no or moderate fibrosis (low fibrosis grade; METAVIR scores F0-F2), or severe fibrosis-to-cirrhosis (high fibrosis grade; METAVIR scores F3-F4) [20, 21].

Samples were collected during the course of routine clinical follow-up and stored at $-80^{\circ} \mathrm{C}$ until use. For each patient, we tested plasma samples collected before anti-HCV therapy initiation and then, longitudinally across at least 12 weeks and for a maximum of 72 weeks after antiviral therapy initiation.

2.2. Amplification, Cloning, and Sequencing of HCV Core Gene. Viral RNA was isolated from plasma samples presenting VL higher than $2.78 \log _{10} \mathrm{UI} / \mathrm{mL}$ using PureLink ${ }^{\circledR}$ Viral RNA/DNA Mini Kit following the manufacturer's instructions (Invitrogen, Life Technologies, USA). The complete $\mathrm{HCV}$ core encoding sequence was amplified using primers core_EF (5' -CGAAAGGCCTTGTGGTACTG-3', position 272-291) and Core_ER (5'-CTCCCGAACGCAGGGCAC$3^{\prime}$, position 1020-1037), and then primers Core_IF ( $5^{\prime}$-TTGTGGTACTGCCTGATAGGGT-3', position 281-302) and Core_IR (5' -ATGCTTGAGTTGGAGCAGTCG-3', position 956-976) in a nested reverse transcriptase polymerase chain reaction (RT-PCR) generating a $695 \mathrm{bp}$ amplicon. The RT program included incubation at $25^{\circ} \mathrm{C}$ for $5 \mathrm{~min}$ and $60 \mathrm{~min}$ at $37^{\circ} \mathrm{C}$ followed by RT enzyme (Moloney Murine Leukemia Virus Reverse Transcriptase, Thermo Fisher Scientific) deactivation at $94^{\circ} \mathrm{C}$ for $15 \mathrm{~min}$. The first PCR program included 40 cycles each of $30 \mathrm{~s}$ at $94^{\circ} \mathrm{C}, 30 \mathrm{~s}$ at $48^{\circ} \mathrm{C}$, and $1 \mathrm{~min}$ at $72^{\circ} \mathrm{C}$ using a Taq DNA polymerase (PB-L, Argentina), followed by a final extension at $72^{\circ} \mathrm{C}$ for $5 \mathrm{~min}$. The PCR product was used in the nested PCR and the program included 25 cycles of $30 \mathrm{~s}$ at $94^{\circ} \mathrm{C}, 30 \mathrm{~s}$ at $48^{\circ} \mathrm{C}, 1 \mathrm{~min}$ at $72^{\circ} \mathrm{C}$, and a final extension of $72^{\circ} \mathrm{C}$ for $5 \mathrm{~min}$. PCR products were resolved by electrophoresis on $1 \%$ agarose gels.

At intrahost level, the HCV core sequence analysis involved the purification and cloning of those amplicons obtained at two most distantly separated sampling times including baseline with the pGEM $^{\circledR}-\mathrm{T}$ Easy Vector System (Promega) according to the manufacturer's instructions. The constructs generated were used to transform DH5 $\alpha$ Escherichia coli competent cells. Thirteen to twenty white colonies were screened by colony PCR for each of the 31 samples for sequence analysis. Plasmid inserts were amplified using pGEM ${ }^{\circledR}$-T-specific primers T7 and SP6 and subjected to double stranded sequence analysis with dye-labeled dideoxy terminators with both T7 and SP6 primers (genetic analyzer 3500xL, Applied Biosystems ${ }^{\circledR}$, Life Technologies, USA). The core sequences from the two sampling time points selected (or only baseline in the case of the nonresponder patient 
TABLE 1: Demographic, clinical, immunologic, and virologic characteristics of the patients studied.

\begin{tabular}{|c|c|c|c|c|c|c|}
\hline Patient & Gender & $\begin{array}{l}\text { Basal CD4 }{ }^{+} \\
\left(\text {cells } / \mathrm{mm}^{3}\right)\end{array}$ & $\begin{array}{l}\text { HCV VL range } \\
\left(\log _{10} \mathrm{UI} / \mathrm{mL}\right)^{\dagger}\end{array}$ & $\begin{array}{c}\text { Fibrosis grade } \\
\text { (METAVIR score) }\end{array}$ & $\begin{array}{c}\text { Response to } \\
\text { IFN-based therapy }\end{array}$ & Sampling times* \\
\hline A & $\mathrm{F}$ & $\mathrm{U}$ & $<2.78-6.5$ & 0 & $\mathrm{R}$ & $\begin{array}{l}0,24 \mathrm{~h}, 4 \mathrm{wk}, 12 \mathrm{wk}, \\
24 \mathrm{wk}, 48 \mathrm{wk}, 72 \mathrm{wk}\end{array}$ \\
\hline B & $\mathrm{F}$ & 644 & $4.5-6.7$ & 4 & NR & $\begin{array}{c}0,24 \mathrm{~h}, 4 \mathrm{wk}, 12 \mathrm{wk}, \\
24 \mathrm{wk}\end{array}$ \\
\hline $\mathrm{C}$ & M & 304 & $5.3-6.8$ & 2 & NR & $\begin{array}{c}0,24 \mathrm{~h}, 4 \mathrm{wk}, 12 \mathrm{wk} \\
24 \mathrm{wk}\end{array}$ \\
\hline $\mathrm{E}$ & M & 957 & $<2.78-6.1$ & 3 & NR & $\begin{array}{c}0,24 \mathrm{~h}, 3 \mathrm{wk}, 12 \mathrm{wk} \\
24 \mathrm{wk}\end{array}$ \\
\hline G & M & 376 & $<2.78-6.8$ & 2 & NR & $\begin{array}{l}0,24 \mathrm{~h}, 4 \mathrm{wk}, 12 \mathrm{wk}, \\
24 \mathrm{wk}, 48 \mathrm{wk}, 72 \mathrm{wk}\end{array}$ \\
\hline $\mathrm{H}$ & M & 130 & $5.3-7.1$ & 0 & NR & $0,24 \mathrm{~h}, 4 \mathrm{wk}, 24 \mathrm{wk}$ \\
\hline$J$ & M & 817 & $3.6-7.1$ & 1 & NR & $\begin{array}{c}0,24 \mathrm{~h}, 4 \mathrm{wk}, 12 \mathrm{wk}, \\
24 \mathrm{wk}\end{array}$ \\
\hline K & M & 400 & $6.4-6.7$ & 4 & NR & $0,24 \mathrm{~h}, 4 \mathrm{wk}, 12 \mathrm{wk}$ \\
\hline $\mathrm{L}$ & M & 625 & $5.9-7.4$ & 3 & NR & $0,24 \mathrm{~h}, 4 \mathrm{wk}, 12 \mathrm{wk}$ \\
\hline M & M & 414 & $4.2-6.3$ & 3 & NR & $\begin{array}{c}0,24 \mathrm{~h}, 4 \mathrm{wk}, 12 \mathrm{wk}, \\
24 \mathrm{wk}\end{array}$ \\
\hline $\mathrm{N}$ & M & 303 & $6.0-6.6$ & 2 & NR & $\begin{array}{c}0,24 \mathrm{~h}, 4 \mathrm{wk}, 12 \mathrm{wk} \\
24 \mathrm{wk}\end{array}$ \\
\hline $\mathrm{P}$ & M & 622 & $<2.78-7.0$ & 1 & NR & $\begin{array}{c}0,24 \mathrm{~h}, 4 \mathrm{wk}, 12 \mathrm{wk}, \\
24 \mathrm{wk}\end{array}$ \\
\hline Q & M & 468 & $<2.78-6.2$ & 4 & NR & $\begin{array}{l}0,24 \mathrm{~h}, 4 \mathrm{wk}, 12 \mathrm{wk}, \\
24 \mathrm{wk}, 48 \mathrm{wk}, 72 \mathrm{wk}\end{array}$ \\
\hline $\mathrm{R}$ & M & $\mathrm{U}$ & $<2.78-7.5$ & 0.5 & $\mathrm{R}$ & $\begin{array}{l}0,24 \mathrm{~h}, 4 \mathrm{wk}, 12 \mathrm{wk}, \\
24 \mathrm{wk}, 48 \mathrm{wk}, 72 \mathrm{wk}\end{array}$ \\
\hline S & M & 262 & $5.8-7.2$ & 1 & NR & $\begin{array}{c}0,24 \mathrm{~h}, 4 \mathrm{wk}, 12 \mathrm{wk}, \\
24 \mathrm{wk}\end{array}$ \\
\hline $\mathrm{U}$ & M & 842 & $<2.78-6.7$ & 4 & $\mathrm{R}$ & $\begin{array}{c}0,24 \mathrm{~h}, 4 \mathrm{wk}, 12 \mathrm{wk} \\
24 \mathrm{wk}, 48 \mathrm{wk}\end{array}$ \\
\hline $\mathrm{X}$ & M & 483 & $<2.78-6.1$ & 1 & NR & $\begin{array}{c}0,24 \mathrm{~h}, 4 \mathrm{wk}, 12 \mathrm{wk} \\
24 \mathrm{wk}\end{array}$ \\
\hline Z & $\mathrm{M}$ & $\mathrm{U}$ & $<2.78$ & 4 & $\mathrm{R}$ & $\begin{array}{l}0,24 \mathrm{~h}, 4 \mathrm{wk}, 12 \mathrm{wk}, \\
24 \mathrm{wk}, 48 \mathrm{wk}, 72 \mathrm{wk}\end{array}$ \\
\hline
\end{tabular}

${ }^{*}$ From basal; U: unknown; ${ }^{\dagger}$ minimum and maximum values measured during the follow-up.

E or responder patients) were edited and assembled using Sequencher software v.5.0.1 (Gene Codes Corporation, Ann Arbor, MI, USA).

Though PCR mutations are a well-known problem, our pipeline for clonal analysis included amplifications that were performed using sufficient molecules as template in order to minimize the error rate due to PCR.

2.3. Phylogenetic Analysis. Sequence alignments were obtained with the MAFFT program implementing iterative refinement, weighted sum-of-pair and scores, and a consistency score obtained from local alignments [22].

Phylogenetic trees were inferred by FastTree-2 [23], under the GTR + CAT model. FastTree automatically scales the tree searching effort proportionally to the number of sequences in the dataset [i.e., the program performs up to $4 \times \log 2(N)$ rounds of minimum-evolution nearest neighbor interchange (NNI), 2 rounds of subtree pruning regrafting (SPR) moves, and up to $2 \times \log (N)$ rounds of maximum likelihood NNIs, where $N$ is the number of unique sequences in the dataset]. We set the program to start from an exhaustive-search BIONJ tree and turned off top-hit heuristics to tree improve searches. Bootstrapping was used to both obtain branch supports and cope with phylogenetic uncertainty in evolutionary analyses. To this aim, we generated 1000 bootstrapped datasets using Seqboot [24] and analyzed the obtained data with FastTree. Phylogenetic diversity measures were obtained from each of these 1000 bootstrapped trees. Branch supports were computed by the CompareToBootstrap.pl script (distributed with FastTree). Trees were visualized and annotated in Dendroscope 3 [25].

2.4. HCV Quasispecies Heterogeneity Analyses. Sequence logos representing DNA and protein sequence alignments were produced using Skylign web server http://skylign.org [26].

Nucleotide sequences were analyzed to assess both interand intrapatient quasispecies heterogeneity dynamics during 


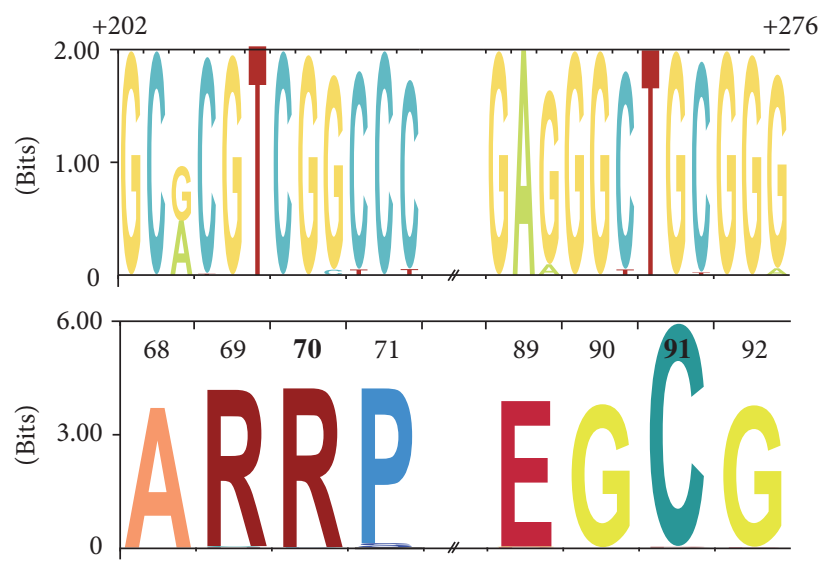

FIGURE 1: Graphical representation of HCV core nucleotide and amino acid sequences from 335 haplotypes. These were obtained from 18 $\mathrm{HCV} / \mathrm{HIV}$ coinfected patients. The total height of each stack corresponds to a measure of the conservation of the column (the information content or entropy of that position expressed in bits). The relative height of each letter within a stack depends on the frequency of that letter at that position. Amino acid positions 70 and 91 are highlighted in bold.

the follow-up. Sequences corresponding to different molecular species were classified as haplotypes. Viral diversity was evaluated from phylogenetic trees, that is, phylogenetic diversity $(P D)$ of Faith which reflects the total length of branches connecting haplotypes along the phylogenetic tree [27]. These analyses were performed using the PD function in the Picante package [28]. Given that diversity indices can be biased by differences in sequence effort, we used a normalized $P D(n-P D)$, which was calculated from (equally sized) subsets of sequences randomly drawn from the original pool of sequences from each sample [29].

\subsection{Intrahost Evaluation of HCV Core Variability and Positive} Selection Pressure. In order to evaluate HCV core variability at each amino acid position was calculated as the entropy, defined as $-\Sigma P(s i) \log P(s i)$, where $P(s i)$ is the probability of a given amino acid $(s)$ appearing at a given position (i). Entropy was computed and the consensus amino acid sequence was determined using the Entropy-ONE Web tool (https://www.hiv.lanl.gov/content/sequence/ENTROPY/entropy_one.html) [30].

Detection of selective pressure was performed using the methods of single likelihood ancestor counting (SLAC) [31], of fixed effects likelihood (FEL), and of mixed effects model of evolution (MEME) [32], as implemented in HyPhy v2.2.1 [33] with online Datamonkey software [34,35]. The analysis was conducted with default options. $d N / d S$ ratio greater than 1 and a $p$ value less than 0.05 was considered to be positively selected. For a higher confidence in the inference of positive selection, only those sites exhibiting coincident results with at least two methods were defined as positively selected sites.

2.6. Statistical Analysis. Quasispecies diversity differences between sampling times in a single patient were calculated by paired-samples Wilcoxon test. Correlations between clinical and quasispecies diversity were evaluated by a regression linear model. All of these were implemented in $\mathrm{R}$ v.3.2.3. A $p$ value 0.05 was considered significant.

\section{Results}

3.1. Nucleotide and Amino Acid Variability in Core Region of HCV-1a. A total of $407 \mathrm{HCV}$ core gene molecular clones were sequenced from samples obtained before, during, and after anti-HCV peg-IFN + RBV treatment. These sequences corresponded to 335 unique variants (hereinafter haplotypes). All 335 haplotypes were quite similar; they showed a number of nucleotide changes but were mainly synonymous mutations (Figure 1). Since it is known that there are some relevant core amino acid substitutions associated with increased HCC risk and variable response to peg-IFN + RBV treatment in HCV-lb, we searched for those changes in our sequences from core HCV-la isolates. Reported core mutations R70Q and L/C91M were not found. Nevertheless, two HCV-1a haplotypes exhibited two mutations at core (R70P and C91R); we did not find any characteristic mutations of fibrosis. Among 18 patients, any amino acid substitution over time was associated with anti-HCV therapy response.

3.2. Phylogenetic Analysis. All haplotypes characterized were patient-specific, meaning that there were no haplotypes shared between different individuals for the entire followup (Figure 2). In addition, each patient's haplotypes were highly related to each other compared to the haplotypes from other patients (Figure 2), in agreement with previous studies $[36,37]$. The only exceptions were patients $\mathrm{H}$ and $\mathrm{X}$ (and in a lesser extent patient $S$ ), whose sequences were sparse across the phylogeny in the case of patient $\mathrm{H}$ and grouped in two different clades for patient X (Figure 2). As also reported previously, some patients presented temporally structured phylogenies, in which the haplotypes from the same sampling time were closely related in the tree (patients C, G, K, M, N, Q, and S; Figure 2), whereas others showed relatively dispersed phylogenetic patterns (patients B, J, L, and P).

3.3. Phylogenetic Diversity. For intrapatient analyses, $\mathrm{n}-\mathrm{PD}$ values were calculated from each sample and we compared phylogenetic diversity over time for each nonresponder 


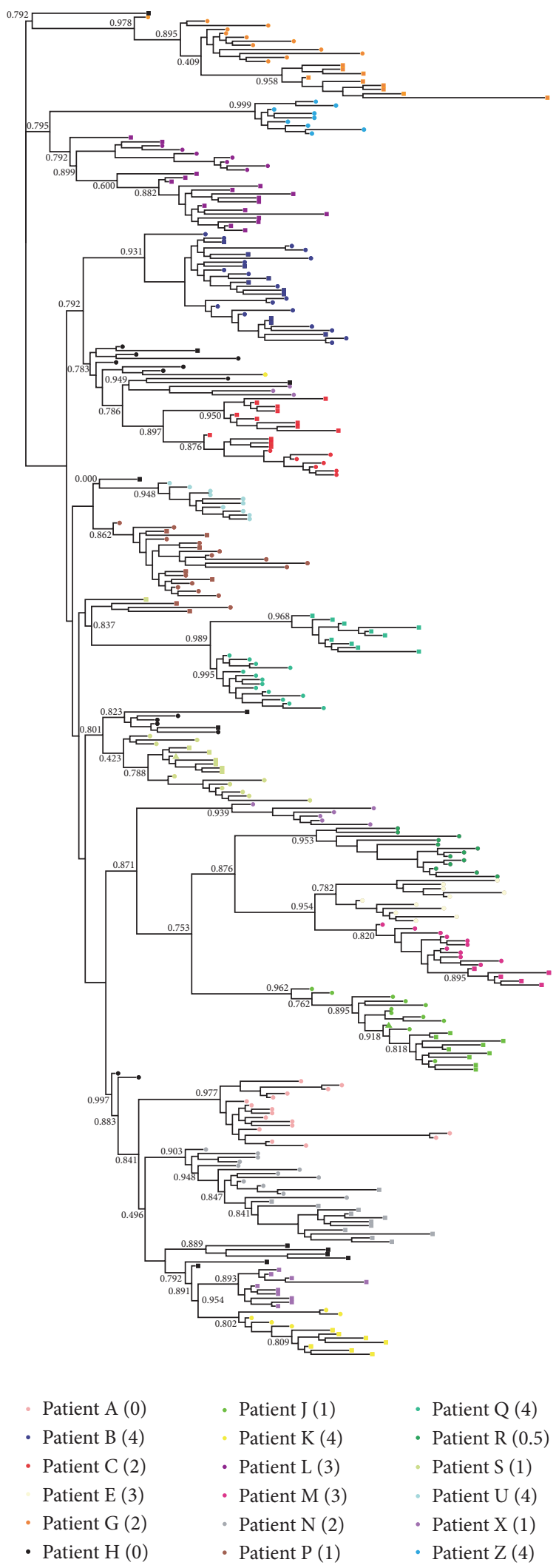

FIGURE 2: Maximum likelihood phylogenetic midpoint routed tree of $335 \mathrm{HCV}$ haplotypes from patients included in the study. Patient-related clusters are identified in different colors with corresponding fibrosis stage between parentheses, as indicated at the top of the figure. Sampling times are coded by symbols (pretreatment: circles; intra- or posttreatment: squares; we coded haplotypes present in both sampling times as triangles). Numbers on branches correspond to relevant bootstrap values. Branch lengths are proportional to the number of nucleotide substitutions per aligned site $(\mathrm{bar}=0.01)$. 

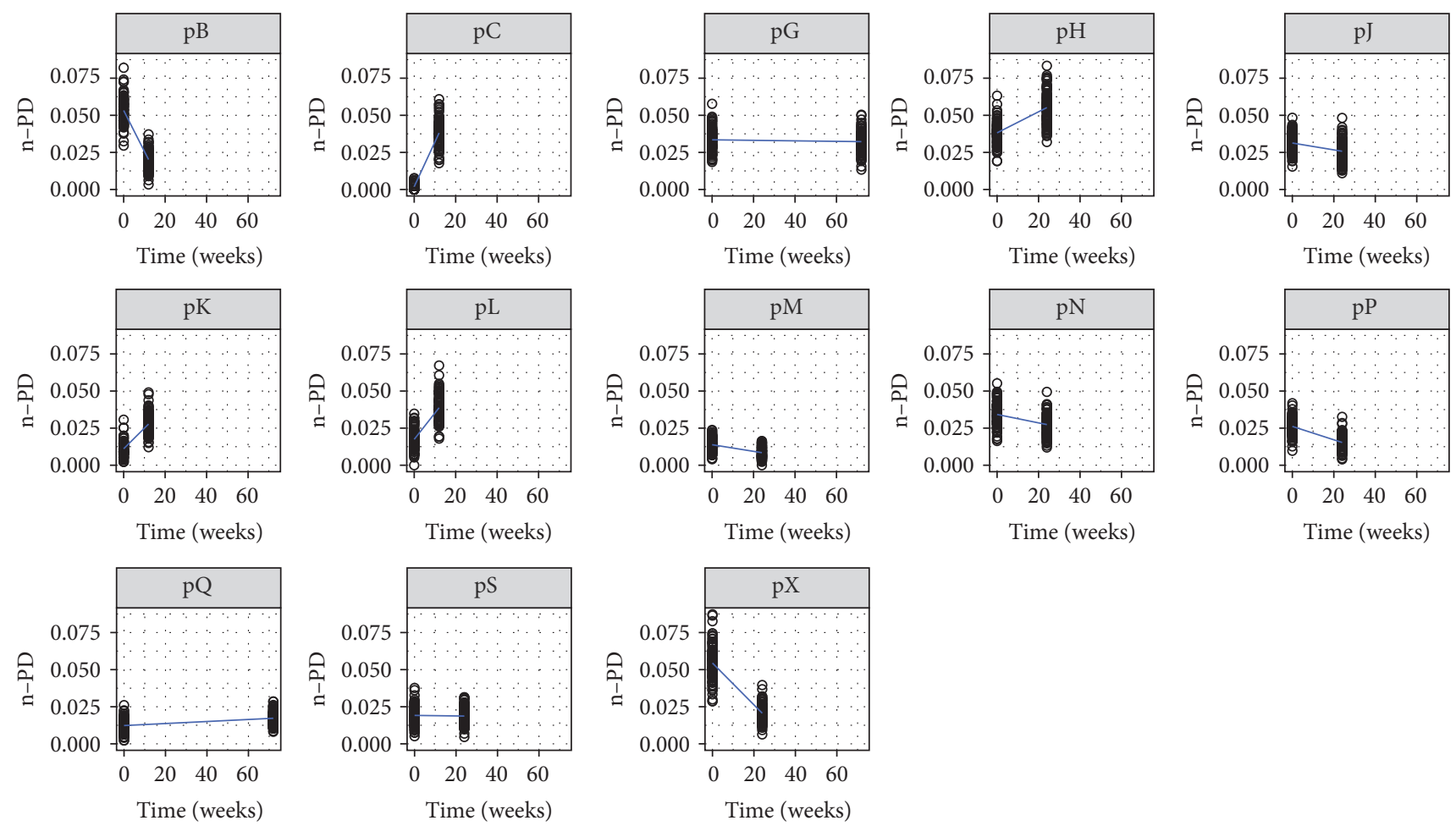

FIGURE 3: Fluctuations in viral population phylogenetic diversity (n-PD). It was measured during the follow-up of nonresponders to IFN + RBV therapy HCV/HIV coinfected patients. Patients are identified by "p" (patient) letter followed by their letter code.

patient with the exception of patient $\mathrm{E}$ because it was not possible to amplify some samples taken at least 12 weeks after therapy initiation. Differences between pretreatment and intra- (or post-) treatment samples were statistically significant for almost every nonresponder patients (Wilcoxon test, $p<0.01$ ) with the exception of patients $G$ and $S$ (Wilcoxon test, $p>0.05$ ). As depicted in Figure 3, viral diversity increased in patients $\mathrm{C}, \mathrm{H}, \mathrm{K}, \mathrm{L}$, and $\mathrm{Q}$ over time, whereas in patients $\mathrm{B}, \mathrm{J}, \mathrm{M}, \mathrm{N}, \mathrm{P}$, and $\mathrm{X}$, it decreased. We evaluated both correlations between these different fluctuations and CD4+ T lymphocytes total counts before therapy initiation or initial variability but no significant associations were found (simple linear regression, $p>0.05$ ). Next, we separated nonresponder patients according to the evolution of viral diversity during treatment (i.e., an increase or a decrease) and we found that $\mathrm{CD} 4+\mathrm{T}$ cell count pretreatment ranges overlapped (initial n-PD $<$ final n-PD, CD4 $+=[303-625]$ cells/mm3; initial $n-P D>$ final $n-P D, C D 4+=[262-817]$ cells/mm3).

\subsection{Phylogenetic Diversity in Core Region of HCV-1a as a} Factor Associated with Fibrosis Severity. Due to conventional amino acid sequences, the analysis of core HCV-la did not exhibit mutations associated with HCC risk as occurs for the same protein in HCV-1b. We analyzed phylogenetic relationships among HCV haplotypes from each sample obtained before therapy initiation and their relationship with fibrosis stages. Maximum Likelihood analyses recovered monophyletic groups from each patient with bootstrap values higher than $70 \%$ but no clustering according to the fibrosis stage was observed (Figure 4).

As mentioned above, $P D$ has been little studied in HCV. Here, we assessed the relationship between a corrected $P D$ measure ( $n-P D$; Materials and Methods) and fibrosis grade $(F G)$. We calculated the virus $P D s$ in all the studied patients and plotted the obtained results against the corresponding $F G s$. With $P D$ being a phylogenetic index, it can be influenced by phylogenetic uncertainty, a frequently neglected but potentially important issue. Thus, to assess potential biases due to this phenomenon, we generated a sample of 1000 bootstrap trees and $P D s$ were obtained from each of these trees. Figure 5 displays boxplots corresponding to $P D s$ obtained from several patients categorized by the corresponding FGs. Interestingly, the analysis revealed a negative relationship between the studied variables $(p<0.01)$, suggesting that the progression towards severe fibrosis stages may be associated with a decrease of $P D$.

A large number of studies have shown that there might be a relationship between $\mathrm{CD} 4+\mathrm{T}$ cell counts and the severity of hepatic damage, but neither fibrosis nor viral diversity showed any association with CD4+ T cell total count among the studied patients (data not shown).

3.5. Intrahost Selection Pressure Analysis in Core Region. We analyzed concomitantly the selection pressure with three methods (SLAC, FEL, and MEME) from each patient and time sampling. As we had expected because of the high homogeneity in our sequences, we found only one site classified coincidently by FEL and MEME methods under positive 


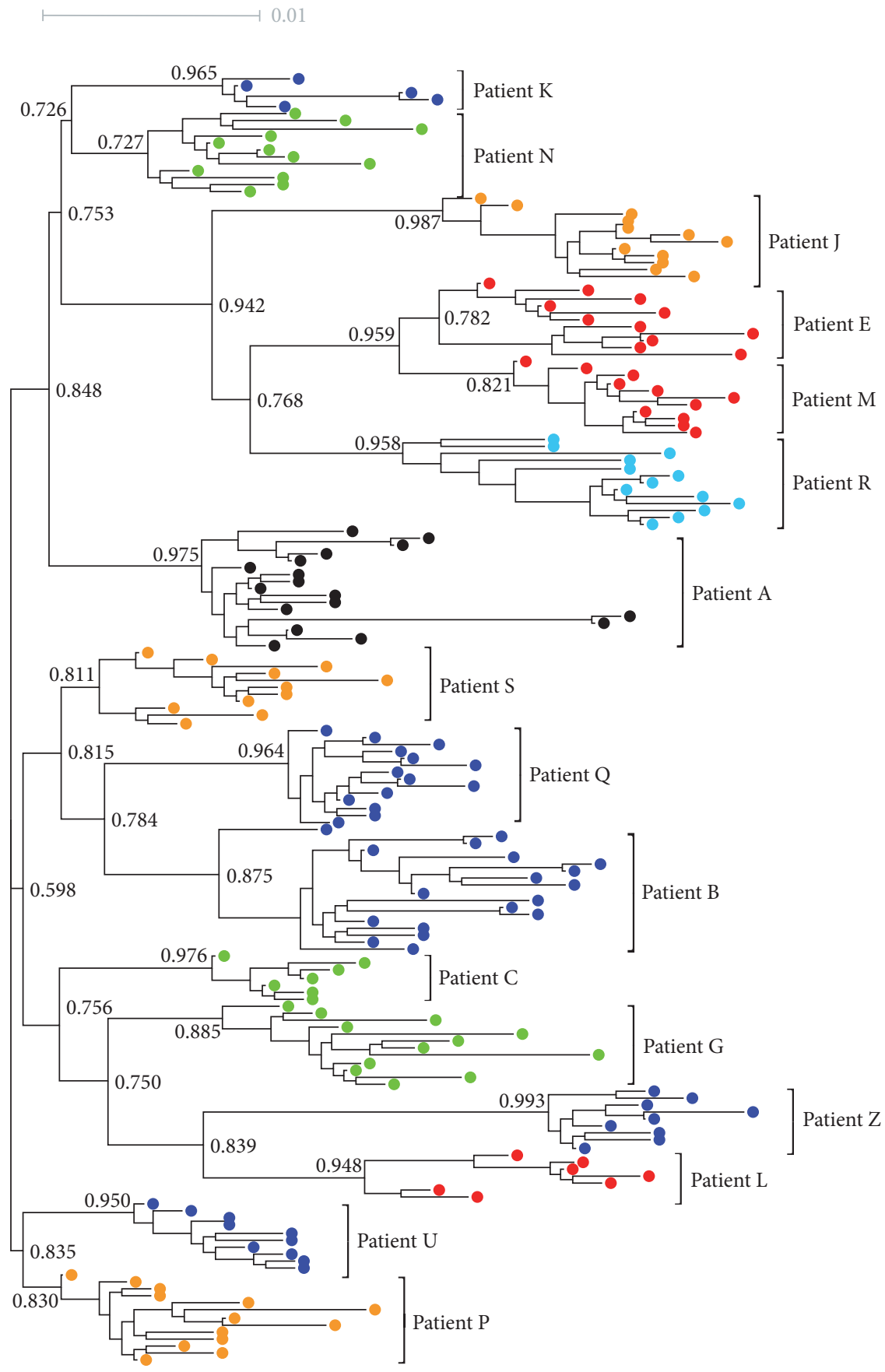

- Fibrosis 0

- Fibrosis 0.5

O Fibrosis 1
- Fibrosis 2

- Fibrosis 3

- Fibrosis 4

FIGURE 4: Maximum likelihood phylogenetic midpoint routed tree of $182 \mathrm{HCV}$ haplotypes isolated from baseline (pretreatment) samples. Fibrosis score (measured within 12 weeks before IFN + RBV therapy initiation) is identified in different colors as indicated at the top of the figure. Haplotypes isolated from the same patient are indicated with patient letter next to the cluster. Some bootstrap values are given on branches. Branch lengths are proportional to the number of nucleotide substitutions per aligned site (bar $=0.01$ ). 

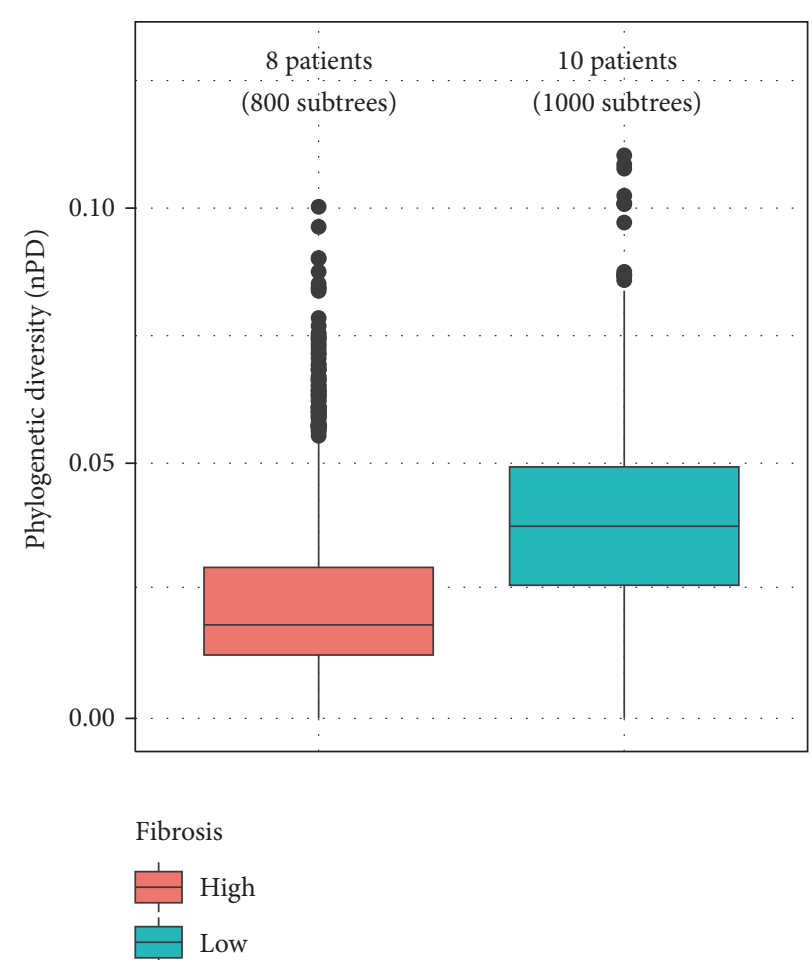

FIGURE 5: Pretreatment HCV phylogenetic diversity (n-PD) categorized by fibrosis grade in HCV/HIV coinfected patients. The boxplots represent the obtained results from 100 bootstrap trees. Lines over the boxes correspond to mean values, whereas boxes themselves indicate 1st and 3rd quartiles; whiskers show the maximum and minimum values, excluding the outliers values, which are represented by dots.

TABLE 2: Integrative selection analysis for HCV-core. NS: not significant.

\begin{tabular}{lcccc}
\hline Patient & Codon & $\begin{array}{c}\text { SLAC } \\
p \text { value }\end{array}$ & $\begin{array}{c}\text { FEL } \\
p \text { value }\end{array}$ & $\begin{array}{c}\text { MEME } \\
p \text { value }\end{array}$ \\
\hline $\mathrm{C}$ & 169 & NS & 0.04 & NS \\
$\mathrm{H}$ & 75 & NS & 0.03 & 0.03 \\
\hline
\end{tabular}

selection in patient $\mathrm{H}$ (Table 2). No positively selected sites were reported by SLAC method.

\section{Discussion}

Core is the most highly conserved of all HCV proteins. Although core sequences are highly similar it is known that a few amino acid mutations can be associated with HCC risk and worse prognosis likely to changes in conformation and then function and protein stability. Many polymorphisms could alter predicted RNA motifs regulating oncogenic processes in a different way [38-40].

In terms of the variability in core alignments, we found both nucleotide and amino acid mutations with a variable prevalence in all patients and sampling times. However, most amino acid sequences were identical to the reference as reported elsewhere [41]. This high level of protein sequence conservation is expected since HCV core is associated with cellular pathways involved in the life cycle of the virus [42, 43].
Fibrosis progression in $\mathrm{HCV}$-infected patients can evolve in HCC as a consequence of cirrhotic damage. Core protein has been marked as an important element in this process because it can interact with a wide variety of cellular proteins modulating cellular proliferation and apoptosis $[44,45]$. Furthermore, the effects of genetic polymorphisms may interact with viral replication itself. R70Q and L/C91M mutations have been frequently associated with HCC risk and variable response to IFN + RBV therapy. However, we did not find any specific mutations from nonresponder patients or severe fibrosis-to-cirrhosis in this cohort of HCV lacoinfected patients. Furthermore, we did not find a positive selection for non-R70 variants during IFN + RBV therapy as reported before [46]. Majorly intrahost HCV evolution in our patients was characterized by a consistent negative selection over time, suggesting the increasing $\mathrm{HCV}$ adaptation to the host in chronic infection. This is in line with the recently reported analysis across all HCV genotypes, where codon positions appeared rarely identified to be positively selected and predominantly found to be under negative selective pressure, suggesting mainly a neutral evolution [47]. It seems clear that our finding is the result of the characteristics of patients selected for the present study who were infected with HCV-la genotype, also observed in previous studies [48-50]. Despite the retrospective nature and the small sample size of our study, our results may suggest that R70Q and L/C91M key mutations are typical of $\mathrm{HCV}$ lb-infected patients and they should not necessarily be associated with HCC risk or prognosis predictor in HCV la-infected individuals. 
Interestingly, in our analysis we also observed that viral diversity before IFN + RBV combined therapy initiation was not associated with a nonresponder or a responder condition. In this sense, the results of the literature are controversial. While some authors argue that baseline diversity is higher in nonresponders, others argue that response to therapy is independent of initial diversity [51]. As observed in this study, diversity during follow-up of nonresponders varied without a fixed pattern. This supports the hypothesis that HCV evolution dynamics is patient-dependent [52, 53]. In this sense, there is evidence that genetic background of each study population should be considered in these analyses $[54,55]$. An interesting example of the complexity of this interaction is offered by R70Q mutation. This substitution is associated with therapy failure in genotype $1 \mathrm{~b}$. However, it is the most common mutation in genotypes 5 and 6 . HCV genotype 5 appears to be an easy-to-treat virus with response rates similar to those of genotypes 2 and 3 after a 48-week course of therapy. Response to treatment in patients with HCV genotype 6 may be at an intermediate level between the observed in genotype 1 and genotype 2 or 3 [56] but a limited number of patients have been studied till present.

We have observed synonymous point mutations in all haplotypes. Sometimes, the same nucleotide change was present in quasispecies isolated from different patients, but each individual showed haplotypes with a unique combination of mutations. A limited number of specific changes in defined positions of the gene could explain, in some way, different profibrotic potentials of core protein. Another possibility should not be ruled out: real profibrotic variants could exist and persist because of their greater fitness. Although a high number of population and clonal sequences were obtained, the conditions for enrolled patients (HCV genotype la and HIV coinfection) limited the number of patients in the present study. A power study is deserved to reach a stronger signal from the dataset in order to observe eventual amino acid substitutions in the core genetic region.

By phylogenetic analyses we have observed that the viral haplotypes associated with each fibrosis score did not seem to be related to each other but were clustered in a patientdependent manner representing a virus-to-host adaptation of HCV in chronic infection and IFN-based therapy, as observed in a previous study of $\mathrm{HCV} 1 \mathrm{~b}$-infected patients [57]. However, a sparse HCV haplotypes distribution was observed in some cases (more prominently $\mathrm{H}$ and $\mathrm{X}$ ) which may reflect eventual mixed infection (or superinfection) with different HCV-1a strains. Considering that HCV variants prevalent at different stages of infection may have specific immunological properties and that $\mathrm{HCV}$-specific adaptive immune response may be impaired in HIV coinfected patients, the selection pressure on the pool complex of viral variants to achieve a stable adaptation to the host may not still occur in these patients.

Decreased HCV genetic heterogeneity could be interpreted both as a cause or a consequence of increased liver damage. In line with the hypothesis that considers the level of viral diversity as the cause of the tissue status several studies have suggested the idea that baseline diversity of $\mathrm{HCV}$ population is an indicator of hepatic disease progression including those performed in HCV-monoinfected [58, 59], $\mathrm{HCV} / \mathrm{HIV}$ coinfected adults [60], and transplant patients chronically infected with $\mathrm{HCV}[61,62]$. Regarding the second hypothesis Harouaka et al. [63] argued that the architecture of tumoral hepatic tissue would be associated with restrictions in HCV replication. This could explain the low diversity in the quasispecies population present in more severe fibrosis stages. If this were the case, phylogenetic diversity could be a potential, noninvasive indicator of liver harm but further investigation is deserved.

In conclusion, we have observed no relationships between particular HCV-1a core polymorphisms and fibrosis severity or response to IFN + RBV therapy in $\mathrm{HCV} / \mathrm{HIV}$ coinfected patients. On the other hand, we observed a significant relationship between fibrosis degree and HCV-la core $P D$, which, in a multifactorial scenario, appears to be a relevant $\mathrm{HCV}$ related factor involved in the progression of chronic hepatitis C. However, our results should be interpreted cautiously considering the low number of cases, potential selection bias, and the retrospective nature of the study. It deserves further investigation including longitudinal studies and analyses of other covariates so that a definite conclusion may be drawn.

\section{Additional Points}

Availability of Data and Material. GenBank accession numbers for HCV core nucleotide sequences are MF622203 to MF622537. The datasets used and/or analyzed during the current study are available from the corresponding author on reasonable request.

\section{Ethical Approval}

All procedures performed in studies involving human participants were in accordance with the ethical standards of the institutional and/or national research committee and with the 1964 Helsinki declaration and its later amendments or comparable ethical standards. The protocol used was evaluated and approved by the Fundación Huésped Ethics Board Committee.

\section{Consent}

Informed consent was obtained from all individual participants included in the study during sample collection.

\section{Disclosure}

All participants recruited in the present study had been included in a larger, previous project. The latter involved clinical, virological, and epidemiological aspects of the $\mathrm{HIV} / \mathrm{HCV}$ coinfection. This article does not contain any studies with animals performed by any of the authors.

\section{Conflicts of Interest}

The authors declare that they have no conflicts of interest. 


\section{Authors' Contributions}

Micaela Parra, Leandro R. Jones, and Jorge Quarleri conceived and designed the experiments. Micaela Parra performed the experiments. Micaela Parra, Natalia Laufer, Julieta M. Manrique, Leandro R. Jones, and Jorge Quarleri analyzed the data. Natalia Laufer performed medical supervision. Leandro R. Jones, Julieta M. Manrique, and Jorge Quarleri contributed reagents/materials/analysis tools. Micaela Parra, Leandro R. Jones, and Jorge Quarleri wrote the paper. Micaela Parra, Julieta M. Manrique, Leandro R. Jones, and Jorge Quarleri designed the software used in analysis.

\section{Acknowledgments}

Micaela Parra was a fellowship holder from Consejo Interuniversitario Nacional (CIN). The work is part of Micaela Parra's final work to obtain her biology degree (equivalent to a master degree in USA). The authors thank Andrea Rubio and Lucas Zapata for their technical assistance and Sergio Mazzini for his assistance during manuscript preparation. This study was funded by grants obtained by Jorge Quarleri from University of Buenos Aires (20020150100033BA) and the Argentinean National Scientific and Technical Research Council (Grant no. PIP-11220110101089).

\section{References}

[1] E. Gower, C. C. Estes, S. Hindman, K. Razavi-Shearer, and H. Razavi, "Global epidemiology and genotype distribution of the hepatitis C virus," Journal of Hepatology, 2014.

[2] L. N. Clausen, L. F. Lundbo, and T. Benfield, "Hepatitis C virus infection in the human immunodeficiency virus infected patient," World Journal of Gastroenterology, vol. 20, no. 34, pp. 12132-12143, 2014.

[3] R. Fischer, T. Baumert, and H. E. Blum, "Hepatitis C virus infection and apoptosis," World Journal of Gastroenterology, vol. 13, no. 36, pp. 4865-4872, 2007.

[4] D. Kralj, L. V. Jukić, S. Stojsavljević, M. Duvnjak, M. Smolić, and I. B. Čurčić, "Hepatitis C virus, insulin resistance, and steatosis," Journal of Clinical and Translational Hepatology, vol. 4, no. 1, pp. 66-75, 2016.

[5] S. Blackham, A. Baillie, F. Al-Hababi et al., "Gene expression profiling indicates the roles of host oxidative stress, apoptosis, lipid metabolism, and intracellular transport genes in the replication of hepatitis C virus," Journal of Virology, vol. 84, no. 10, pp. 5404-5414, 2010.

[6] A. Banerjee, R. B. Ray, and R. Ray, "Oncogenic potential of hepatitis C virus proteins," Viruses, vol. 2, no. 9, pp. 2108-2133, 2010.

[7] L. B. Seeff, "Natural history of chronic hepatitis C", Hepatology, vol. 36, no. 5, pp. S35-S46, 2002.

[8] J. M. Miro, P. Stock, E. Teicher, J.-C. Duclos-Vallée, N. Terrault, and A. Rimola, "Outcome and management of HCV/HIV coinfection pre- and post-liver transplantation. A 2015 update," Journal of Hepatology, vol. 62, no. 3, pp. 701-711, 2015.

[9] E. Domingo, J. Sheldon, and C. Perales, "Viral quasispecies evolution," Microbiology and Molecular Biology Reviews, vol. 76, no. 2, pp. 159-216, 2012.
[10] C. C. Kao, G. Yi, and H. Huang, "The core of hepatitis C virus pathogenesis," Current Opinion in Virology, vol. 17, pp. 66-73, 2016.

[11] N. Akuta, F. Suzuki, Y. Kawamura et al., "Amino acid substitutions in the hepatitis $\mathrm{C}$ virus core region are the important predictor of hepatocarcinogenesis," Hepatology, vol. 46, no. 5, pp. 1357-1364, 2007.

[12] N. Akuta, F. Suzuki, Y. Seko et al., "Complicated relationships of amino acid substitution in hepatitis $\mathrm{C}$ virus core region and IL28B genotype influencing hepatocarcinogenesis," Hepatology, vol. 56, no. 6, pp. 2134-2141, 2012.

[13] Y. Seko, N. Akuta, F. Suzuki et al., "Amino acid substitutions in the hepatitis $\mathrm{C}$ virus core region and lipid metabolism are associated with hepatocarcinogenesis in nonresponders to interferon plus ribavirin combination therapy," Intervirology, vol. 56, no. 1, pp. 13-21, 2012.

[14] P. Barreiro, L. Martín-Carbonero, M. Núñez et al., "Predictors of liver fibrosis in HIV-infected patients with chronic hepatitis $\mathrm{C}$ virus (HCV) infection: Assessment using transient elastometry and the role of HCV genotype 3," Clinical Infectious Diseases, vol. 42, no. 7, pp. 1032-1039, 2006.

[15] M.-A. Loko, L. Castera, F. Dabis et al., "Validation and comparison of simple noninvasive indexes for predicting liver fibrosis in HIV-HCV-coinfected patients: ANRS CO3 Aquitaine Cohort," American Journal of Gastroenterology, vol. 103, no. 8, pp. 19731980, 2008.

[16] M. Matas, A. Picornell, C. Cifuentes et al., "Relating the liver damage with hepatitis $\mathrm{C}$ virus polymorphism in core region and human variables in HIV-1-coinfected patients," Infection, Genetics and Evolution, vol. 10, no. 8, pp. 1252-1261, 2010.

[17] M. Matas, A. Picornell, C. Cifuentes et al., "Generalized Linear Model (GLM) framework for the association of host variables and viral strains with liver fibrosis in HCV/HIV coinfected patients," Infection, Genetics and Evolution, vol. 13, no. 1, pp. 284-291, 2013.

[18] P. Bedossa, D. Dargère, and V. Paradis, "Sampling variability of liver fibrosis in chronic hepatitis C," Hepatology, vol. 38, no. 6, pp. 1449-1457, 2003.

[19] EASL., "EASL Clinical Practice Guidelines: management of hepatitis C virus infection," Hepatol, vol. 55, pp. 245-264, 2011.

[20] D. J. T. Bruden, B. J. McMahon, L. Townshend-Bulson et al., "Risk of end stage liver disease, hepatocellular carcinoma, and liver-related death by fibrosis stage in the hepatitis C Alaska Cohort," Hepatology, 2017.

[21] J. A. Cepeda, D. L. Thomas, J. Astemborski, M. S. Sulkowski, G. D. Kirk, and S. H. Mehta, "Increased Mortality Among Persons With Chronic Hepatitis C With Moderate or Severe Liver Disease: A Cohort Study," Clinical Infectious Diseases, vol. 65, no. 2, pp. 235-243, 2017.

[22] K. Katoh and D. M. Standley, "MAFFT: Iterative refinement and additional methods," Methods in Molecular Biology, vol. 1079, pp. 131-146, 2014.

[23] M. N. Price, P. S. Dehal, and A. P. Arkin, "FastTree 2approximately maximum-likelihood trees for large alignments," PLoS ONE, vol. 5, no. 3, Article ID e9490, 2010.

[24] J. Felsenstein, "PHYLIP (Phylogeny Inference Package) version 3.6," pp. 164-166, 2005.

[25] D. H. Huson and C. Scornavacca, "Dendroscope 3: An interactive tool for rooted phylogenetic trees and networks," Systematic Biology, vol. 61, no. 6, pp. 1061-1067, 2012. 
[26] T. J. Wheeler, J. Clements, and R. D. Finn, "Skylign: A tool for creating informative, interactive logos representing sequence alignments and profile hidden Markov models," BMC Bioinformatics, vol. 15, no. 1, article no. 7, 2014.

[27] D. P. Faith, "Conservation evaluation and phylogenetic diversity," Biological Conservation, vol. 61, no. 1, pp. 1-10, 1992.

[28] S. W. Kembel, P. D. Cowan, M. R. Helmus et al., "Picante: R tools for integrating phylogenies and ecology," Bioinformatics, vol. 26, no. 11, pp. 1463-1464, 2010.

[29] D. A. Nipperess, "The Rarefaction of Phylogenetic Diversity: Formulation, Extension and Application," in Biodiversity Conservation and Phylogenetic Systematics, vol. 14 of Topics in Biodiversity and Conservation, pp. 197-217, Springer International Publishing, Cham, 2016.

[30] B. T. M. Korber, K. MacInnes, R. F. Smith, and G. Myers, "Mutational trends in V3 loop protein sequences observed in different genetic lineages of human immunodeficiency virus type 1," Journal of Virology, vol. 68, no. 10, pp. 6730-6744, 1994.

[31] S. L. Kosakovsky Pond and S. D. W. Frost, "Not so different after all: a comparison of methods for detecting amino acid sites under selection," Molecular Biology and Evolution, vol. 22, no. 5, pp. 1208-1222, 2005.

[32] B. Murrell, J. O. Wertheim, S. Moola, T. Weighill, K. Scheffler, and S. L. Kosakovsky Pond, "Detecting individual sites subject to episodic diversifying selection," PLoS Genetics, vol. 8, no. 7, Article ID e1002764, 2012.

[33] S. L. Kosakovsky Pond, S. D. W. Frost, and S. V. Muse, "HyPhy: Hypothesis testing using phylogenies," Bioinformatics, vol. 21, no. 5, pp. 676-679, 2005.

[34] W. Delport, A. F. Y. Poon, S. D. W. Frost, and S. L. Kosakovsky Pond, "Datamonkey 2010: A suite of phylogenetic analysis tools for evolutionary biology," Bioinformatics, vol. 26, no. 19, Article ID btq429, pp. 2455-2457, 2010.

[35] S. L. Kosakovsky Pond and S. D. W. Frost, "Datamonkey: rapid detection of selective pressure on individual sites of codon alignments," Bioinformatics, vol. 21, no. 10, pp. 2531-2533, 2005.

[36] M. Sede, L. R. Jones, F. Moretti, N. Laufer, and J. Quarleri, "Corrigendum to "Inter and intra-host variability of hepatitis C virus genotype la hypervariable envelope coding domains followed for a 4-11 year of human immunodeficiency virus coinfection and highly active antiretroviral therapy" [Virology 471-473 (2014) 19-28]," Virology, vol. 474, pp. 199-200, 2015.

[37] M. Sede, M. Parra, J. M. Manrique, N. Laufer, L. R. Jones, and J. Quarleri, "Evolution of hepatitis C virus in HIV coinfected patients under antiretroviral therapy," Infection, Genetics and Evolution, vol. 43, pp. 186-196, 2016.

[38] A. El-Shamy, M. Pendleton, F. J. Eng, E. H. Doyle, A. Bashir, and A. D. Branch, "Impact of HCV core gene quasispecies on hepatocellular carcinoma risk among HALT-C trial patients," Scientific Reports, vol. 6, Article ID 27025, 2016.

[39] W. M. Ezzat and K. S. Amr, "Insights for hepatitis C virus related hepatocellular carcinoma genetic biomarkers: Early diagnosis and therapeutic intervention," World Journal of Hepatology, vol. 8, no. 30, pp. 1251-1261, 2016.

[40] S. L. Fishman, S. H. Factor, C. Balestrieri et al., "Mutations in the hepatitis $C$ virus core gene are associated with advanced liver disease and hepatocellular carcinoma," Clinical Cancer Research, vol. 15, no. 9, pp. 3205-3213, 2009.

[41] F. S. Alhamlan, M. N. Al-Ahdal, N. Z. Khalaf et al., "Hepatitis $\mathrm{C}$ virus genotype 1 : How genetic variability of the core protein affects the response to pegylated-interferon and ribavirin therapy," Journal of Medical Virology, vol. 86, no. 2, pp. 224-234, 2014.

[42] J. McLauchlan, "Properties of the hepatitis C virus core protein: A structural protein that modulates cellular processes," Journal of Viral Hepatitis, vol. 7, no. 1, pp. 2-14, 2000.

[43] R. B. Ray and R. Ray, "Hepatitis C virus core protein: Intriguing properties and functional relevance," FEMS Microbiology Letters, vol. 202, no. 2, pp. 149-156, 2001.

[44] B. de Chassey, V. Navratil, L. Tafforeau et al., "Hepatitis C virus infection protein network," Molecular Systems Biology, vol. 4, no. 1, article 230, 2008.

[45] M. R. Higgs, H. Lerat, and J.-M. Pawlotsky, "Hepatitis C virusinduced activation of $\beta$-catenin promotes c-Myc expression and a cascade of pro-carcinogenetic events," Oncogene, vol. 32, no. 39, pp. 4683-4693, 2013.

[46] F. Kurbanov, Y. Tanaka, K. Matsuura et al., "Positive selection of core $70 \mathrm{Q}$ variant genotype $1 \mathrm{~b}$ hepatitis $\mathrm{C}$ virus strains induced by pegylated interferon and ribavirin," The Journal of Infectious Diseases, vol. 201, no. 11, pp. 1663-1671, 2010.

[47] L. Cuypers, G. Li, P. Libin, S. Piampongsant, A.-M. Vandamme, and K. Theys, "Genetic diversity and selective pressure in hepatitis $\mathrm{C}$ virus genotypes 1-6: significance for direct-acting antiviral treatment and drug resistance," Viruses, vol. 7, no. 9, pp. 5018-5039, 2015.

[48] E. Alestig, B. Arnholm, A. Eilard et al., "Core mutations, IL28B polymorphisms and response to peginterferon/ribavirin treatment in Swedish patients with hepatitis $C$ virus genotype 1 infection," BMC Infectious Diseases, vol. 11, article no. 124, 2011.

[49] R. C. Jaspe, Y. F. Sulbarán, M. Z. Sulbarán, C. L. Loureiro, H. R. Rangel, and F. H. Pujol, "Prevalence of amino acid mutations in hepatitis C virus core and NS5B regions among Venezuelan viral isolates and comparison with worldwide isolates," Virology Journal, vol. 9, article no. 214, 2012.

[50] D. Kadjbaf, M. Keshvari, S. M. Alavian et al., "The prevalence of hepatitis $\mathrm{C}$ virus core amino acid 70 substitution and genotypes of polymorphisms near the IFNL3 gene in iranian patients with chronic hepatitis C," Hepatitis Monthly, vol. 16, no. 6, Article ID e37011, 2016.

[51] N. Echeverría, G. Moratorio, J. Cristina, and P. Moreno, "Hepatitis $\mathrm{C}$ virus genetic variability and evolution," World Journal of Hepatology, vol. 7, no. 6, pp. 831-845, 2015.

[52] C. Bittar, A. C. G. Jardim, L. H. T. Yamasaki et al., "On Hepatitis C Virus Evolution: The Interaction between Virus and Host towards Treatment Outcome," PLoS ONE, vol. 8, no. 4, Article ID e62393, 2013.

[53] J. Cristina, M. D. P. Moreno, and G. Moratorio, "Hepatitis $\mathrm{C}$ virus genetic variability in patients undergoing antiviral therapy," Virus Research, vol. 127, no. 2, pp. 185-194, 2007.

[54] E. Aparicio, S. Franco, M. Parera et al., "Complexity and catalytic efficiency of hepatitis C virus (HCV) NS3 and NS4A protease quasispecies influence responsiveness to treatment with pegylated interferon plus ribavirin in $\mathrm{HCV} / \mathrm{HIV}$-coinfected patients," Journal of Virology, vol. 85, no. 12, pp. 5961-5969, 2011.

[55] D. Ge, J. Fellay, A. J. Thompson et al., "Genetic variation in IL28B predicts hepatitis C treatment-induced viral clearance," Nature, vol. 461, no. 7262, pp. 399-401, 2009.

[56] M. H. Nguyen and E. B. Keeffe, "Prevalence and treatment of hepatitis C virus genotypes 4, 5, and 6," Clinical Gastroenterology and Hepatology, vol. 3, no. 2, pp. S97-S101, 2005. 
[57] M. Duffy, M. Salemi, N. Sheehy et al., "Comparative rates of nucleotide sequence variation in the hypervariable region of $\mathrm{E} 1 / \mathrm{E} 2$ and the NS5b region of hepatitis C virus in patients with a spectrum of liver disease resulting from a common source of infection," Virology, vol. 301, no. 2, pp. 354-364, 2002.

[58] P. Farci, I. Quinti, S. Farci et al., "Evolution of hepatitis C viral quasispecies and hepatic injury in perinatally infected children followed prospectively," Proceedings of the National Acadamy of Sciences of the United States of America, vol. 103, no. 22, pp. 8475-8480, 2006.

[59] D. G. Sullivan, D. Bruden, H. Deubner et al., "Hepatitis C virus dynamics during natural infection are associated with longterm histological outcome of chronic hepatitis C disease," The Journal of Infectious Diseases, vol. 196, no. 2, pp. 239-248, 2007.

[60] H. Qin, N. J. Shire, E. D. Keenan et al., "HCV quasispecies evolution: Association with progression to end-stage liver disease in hemophiliacs infected with HCV or HCV/HIV," Blood, vol. 105, no. 2, pp. 533-541, 2005.

[61] J. I. Arenas, J. F. Gallegos-Orozco, T. Laskus et al., "Hepatitis $\mathrm{C}$ virus quasi-species dynamics predict progression of fibrosis after liver transplantation," The Journal of Infectious Diseases, vol. 189, no. 11, pp. 2037-2046, 2004.

[62] A. C. Lyra, X. Fan, D. M. Lang et al., "Evolution of hepatitis C viral quasispecies after liver transplantation," Gastroenterology, vol. 123, no. 5, pp. 1485-1493, 2002.

[63] D. Harouaka, R. E. Engle, K. Wollenberg et al., "Diminished viral replication and compartmentalization of hepatitis $C$ virus in hepatocellular carcinoma tissue," Proceedings of the National Acadamy of Sciences of the United States of America, vol. 113, no. 5, pp. 1375-1380, 2016. 


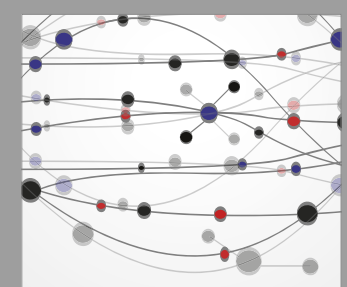

The Scientific World Journal
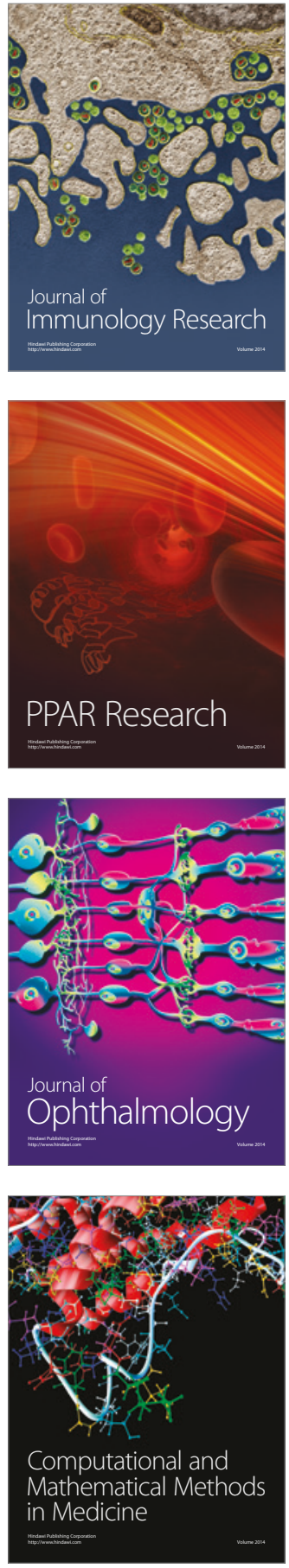

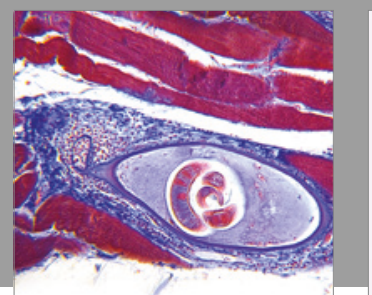

Gastroenterology Research and Practice
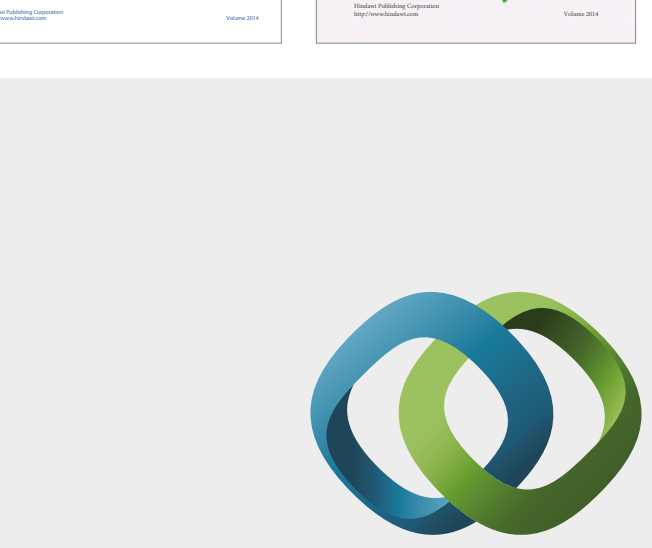

\section{Hindawi}

Submit your manuscripts at

https://www.hindawi.com
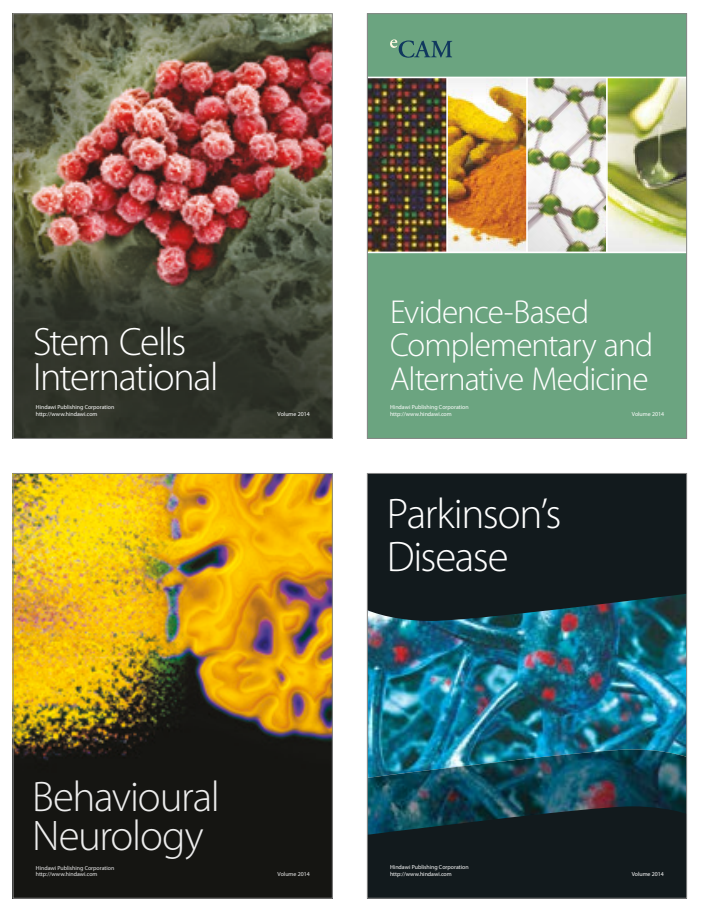
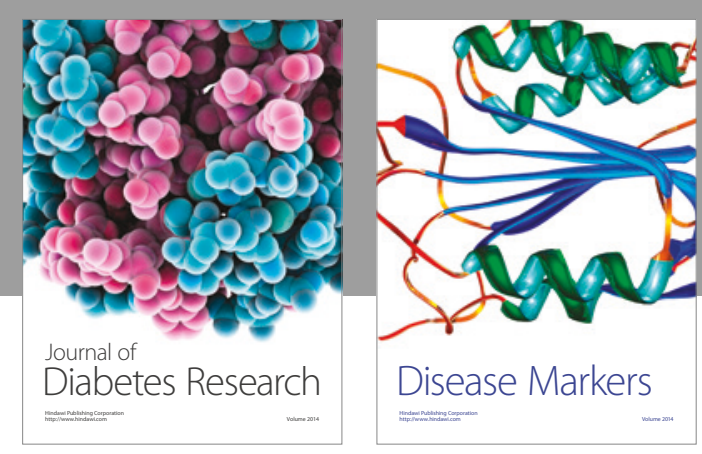

Disease Markers
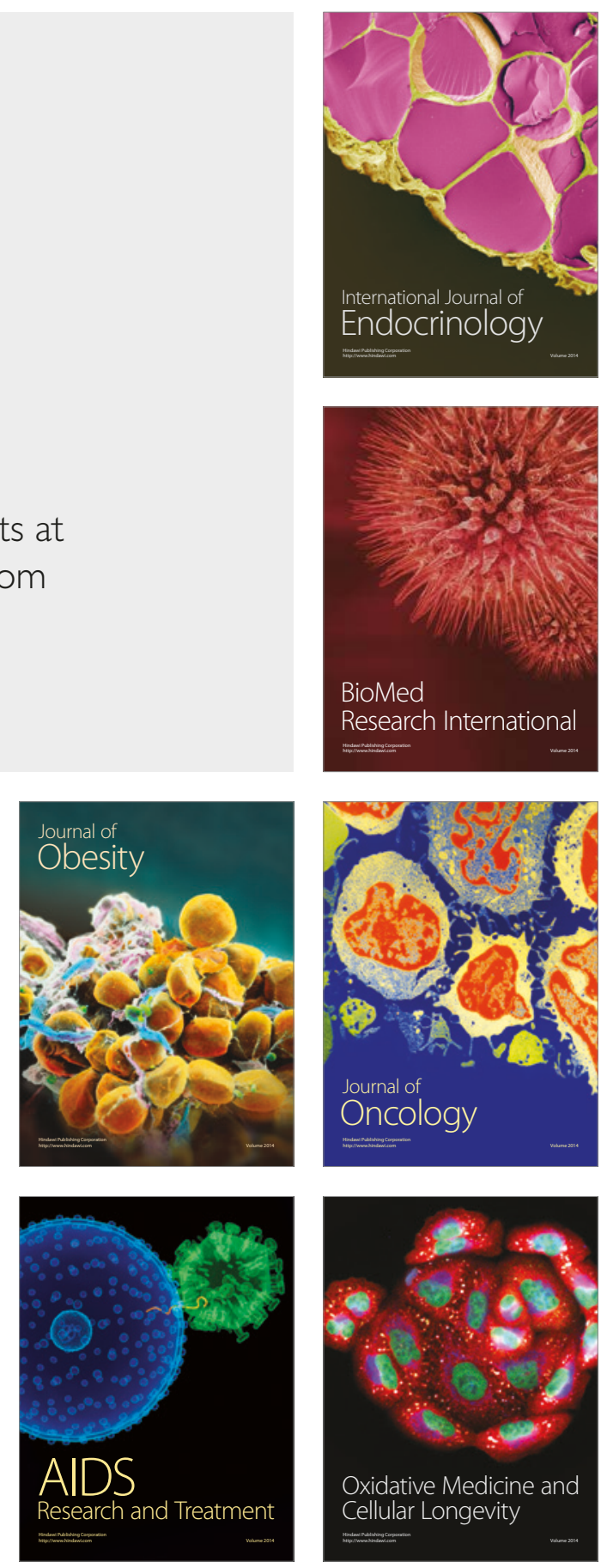